\title{
Effect of sacral neuromodulation on female sexual function and quality of life: Are they correlated?
}

\author{
Mai Banakhar, MD; ${ }^{*}$ Yahya Gazwani, MD; ${ }^{*}$ Mohamed El Kelini, MD; ${ }^{*}$ Tariq Al-Shaiji, MD; ${ }^{\dagger}$ \\ Magdy Hassouna, MD, FRCSC ${ }^{+}$
}

*Department of Urology, King Abdulaziz University, Faculty of Medicine, Jeddah, Kingdom of Saudi Arabia; †Department of Urology, University of Toronto, Toronto Western Hospital, Toronto, ON

Cite as: Can Urol Assoc J 2014;8(11-12):e762-7. http://dx.doi.org/10.5489/cuai.2300 Published online November 24, 2014.

\section{Abstract}

Introduction: Sacral neuromodulation (SNM) has become an established therapy for voiding dysfunction. Additional benefits, such as improved bowel functions and bladder pain, have been reported. Improvement in female sexual function after SNM treatment has been suggested; however, reports examining the effects of SNM on female sexual functions are scarce. We evaluate the effects of SNM on female sexual function and its impact on quality of life and analyze any correlation.

Methods: Data were collected from January 2010 to May 2012 for all female patients who underwent SNM InterStim (Medtronic, Minneapolis, MN) therapy at a single centre in Canada. They were treated for voiding dysfunction, including refractory overactive bladder, frequency-urgency syndrome and non-obstructive urinary retention. Patients were screened by percutaneous nerve evaluation (PNE) to assess their response to therapy using a 4-day voiding diary. Patients who experienced $50 \%$ or more improvement in their voiding parameters were permanently implanted. All patients completed the Female Sexual Function Index (FSFI), Short-Form Health Survey (SF-36), and incontinence questionnaires (Urinary Distress Inventory [UDI]-6) preoperatively and 4 months postoperatively.

Results: A total of 33 female patients had SNM therapy; 10 were excluded from the study because they were not sexually active. The indications were: refractory overactive bladder in 19, frequencyurgency syndrome in 2, and non-obstructive urinary retention in another 2 patients. SNM therapy significantly improved the total FSFI score $(p=0.011)$; the components of desire and orgasm showed significant improvement $(p=0.014$ and $p=0.035$, respectively). Age, body mass index, diagnosis, and urinary symptoms did not show significant correlation with FSFI score improvement. Quality of life showed significant improvement after SNM treatment in 5 categories. There was no correlation between improvement in quality of life and FSFI.

Conclusion: SNM may improve female sexual function and quality of life, yet there is no correlation between the improvement in FSFI and quality of life.

\section{Introduction}

Sacral nerve stimulation (Interstim, Medtronic, Minneapolis, $\mathrm{MN}$ ) has become an established option in the treatment of lower urinary tract symptoms (LUTS). It is an FDA-approved therapy for refractory overactive bladder, frequency-urgency syndrome, and non-obstructive urinary retention. ${ }^{1-5}$

Therapy includes modulation of the third sacral nerve root, using an electrode implanted in the S3 foramen, which is then connected to a pulse generator placed in a subcutaneous pocket over the buttocks. The mechanism of action is not well understood; ${ }^{6-8}$ however, the stimulation of the S3 nerve root modulates the function of nerves arising from the $\mathrm{S} 3$ root. $^{9}$

The nerves arising from the S3 root include pelvic, pudendal nerves which innervate perineal muscle and inferior hypogastric plexus which in turn innervate pelvic organs. Stimulation of these nerves plays a major role for SNM therapy in resolving voiding dysfunction and improving bowel function. ${ }^{10}$

Promising results are being reported in conditions, such as pelvic pain syndrome and interstitial cystitis. ${ }^{11-15}$ Few papers reported the effect of SNM therapy on female sexual function in mixed population groups with voiding dysfunction, fecal incontinence, ${ }^{16}$ and chronic pelvic pain. ${ }^{17-18}$ It is uncertain if the reported effect of SNM therapy in female sexual function is direct to stimulation or secondary to primary disease therapy and overall improved quality of life. Also, measurement of sexual function is notoriously difficult and relies on subjective patient-reported data on a potentially embarrassing topic. ${ }^{19}$ While other studies were limited by small sample size, none validated questionnaires, and retrospective design, which were major study limitations. In this study, we evaluate the effects of SNM on female sexual function and its impact on quality of life; we also analyze any correlation between these factors. 


\section{Methods}

In this prospective, observational study, we evaluated the effect of SNM on female sexual function in voiding dysfunction patients and its impact on quality of life.

The study was approved by our local ethics approval board. The study was conducted at a single centre (Toronto Western Hospital, Toronto, Ontario, Canada) between January 2010 and May 2012. We included female patients undergoing SNM (Interstim) therapy for the following indications: overactive bladder after failed medical treatment, frequency-urgency syndrome, and chronic urinary retention. All patients were screened by percutaneous nerve evaluation (PNE) for 4 days, or a staged procedure for 2 weeks. The InterStim device was implanted in patients who had $50 \%$ or urinary symptom control and improvement on comparing voiding diary before and during the test period.

\section{Outcome measurement}

Our primary outcome was any observed changes in female sexual function associated with the application of pelvic neuromodulation. It was assessed using the validated FSFI questionnaire that assesses the 6 main domains of female sexual function (desire, arousal, orgasm, pain, vaginal lubrication, relationship satisfaction). The total FSFI score is obtained by adding all domains scores. According to Wiegel and colleagues, ${ }^{20}$ a total FSFI score of $\leq 26$ indicates female sexual dysfunction.

Our secondary outcomes included quality of life and urinary symptom control. Quality of life was assessed using the validated Short-Form Health Survey (SF-36), which includes 36 questions assessing 8 quality of life domains (physical functioning, physical role, body pain, general health, vitality, social functioning, emotional role, mental health). The RAND method was used for scoring the SF-36 questionnaire.

Urinary symptoms were assessed using the Urinary Distress Inventory (UDI)-6 questionnaire. This questionnaire includes 6 questions on urine frequency, leakage, lower abdomen discomfort and difficult bladder emptying. Selections include: not at all (score $=0$ ), slightly (score $=1$ ), moderate (score $=2)$, and greatly affected ( total score is calculated by the sum of all questions scores (minimum score 0 , maximum score 18 ).

All forms (FSFI, SF-36, and UDI-6) were completed by all patients preoperatively and an average of 4 months (range: 3-5 months) post-SNM implantation.

\section{Surgical procedure}

All patients underwent a PNE screening test under local anesthesia in an outpatient setting. At our centre, during the PNE we depend on the response location at the anal and perianal area; at follow-up, we request an x-ray to confirm the proper electrode position.

A staged procedure was undertaken if the PNE testing was difficult in terms of foramen localization, if patients could not tolerate the procedure or if there was radiological evidence of electrode migration on the post-testing plain $\mathrm{x}$-ray. Patients who had a positive screening test $(50 \%$ or more subjective and/or objective clinical improvement on voiding diary) underwent the SNM implantation. The procedure was done under general anesthesia with a strict sterile technique and under prophylactic antibiotic coverage. The tined lead electrode was inserted at the right or left third sacral nerve foramen, which was connected to the Interstim device. The device was inserted subcutaneously in the buttock area, right or left depending on the patient's dominant hand side. All devices were turned on and programmed on the same day of implantation and patients were taught how to use the programmer. All patients were instructed to resume their sexual activity after 4 weeks of implantation to avoid electrode migration.

\section{Exclusion criteria}

We excluded patients who were not sexually active (no sexual partner, irrespective of the comorbidity status), who did not fill out the questionnaires or who missed their outpatient follow-up appointments.

\section{Statistical analysis}

Data were collected using Microsoft Excel 2003. Statistical analysis was performed using IBM SPSS 19.0 (SAS Institute, Cary, NC). Descriptive analyses were reported as means and frequencies. Comparison between preoperative and postoperative FSFI, SF-36, and UDI-6 scores was performed using paired sample T-tests. Pearson correlation coefficient analysis was computed between FSFI scores and patient parameters (age, body mass index [BMI], diagnosis, urinary symptom). All values were considered statistically significant at $p \leq 0.05$.

\section{Results}

In total 33 female patients underwent SNM implantation between January 2010 and May 2012. Ten patients were not sexually active and therefore excluded from the study. The indications were: refractory overactive bladder in 19, 
frequency-urgency syndrome in 2, and non-obstructive urinary retention in another 2 patients. The mean age was 51 years (range: $21-71$ ) and the mean BMI was $28.6 \pm 6.3$. Nine patients had a positive history of comorbid factors (diabetes mellitus, hysterectomy). All patients underwent the PNE test, except 1 patient who needed the staged procedure because of electrode migration (Fig. 1, Table 1).

All forms were completed by all patients preoperatively and an average of 4 months post-implantation. Comparing FSFI pre- and post-implantation scores showed that SNM treatment significantly improved the total FSFI score $(p=0.011$, confidence interval $[\mathrm{CI}]-5.1153$ to -5.1153$)$. Desire and orgasm were the only FSFI domains that showed significant improvement with SNM ( $p=0.014, p=0.035$, respectively) (Table 2a, Table $2 \mathrm{~b}$ ). Person correlation coefficient analysis did not show any significant correlation between the improvement in FSFI score and age, BMI, diagnosis, and urinary symptoms (Table 3 ).

Quality of life showed significant improvement after SNM implantation in 5 categories: physical function $(p=0.00)$, energy $(p=0.00)$, emotional well-being $(p=0.005)$, social functioning $(p=0.00)$, and general health $(p=0.001)$ (Table 4).

Statistical analysis showed no correlation between quality of life domains, age, BMI, and the difference in total FSFI score; however, urinary symptom control (UDI-6 score
Table 1. Patient demographics

33 implanted

Total number

23 included

10 excluded, not sexually active

19 Refractory overactive bladder

Diagnosis

Age

Baseline UDI-6

2 Frequency urgency syndrome 2 Non-obstructive urinary retention

BMI

Mean $51 \pm 13$ (range: $21-71$ )

BII

Comorbidity

Screening test

SNM implantation

Mean $8.96 \pm 4.416$ (range: $0-18$ )

Mean $28.6 \pm 6.3$ (range: $18.2-46.7$ )

14 no comorbid factors

9 positive history (diabetes mellitus, hysterectomy)

22 Percutanoeus nerve evaluation test 1 staged

All unilateral

Device type IPG

17 Model 3903

6 InterStim 2

Side

12 Right S3

11 Left S3

Postoperative UDI-6

$5.13 \pm 4.4$

BMI: body mass index; UDI: Urinary Distress Inventory; SNM: sacral neuromodulation; IPG: implantable pulse generator.

difference) showed significant correlation with the social functioning domain of quality of life $(r=-0.419, p=0.047)$ (Table 5).

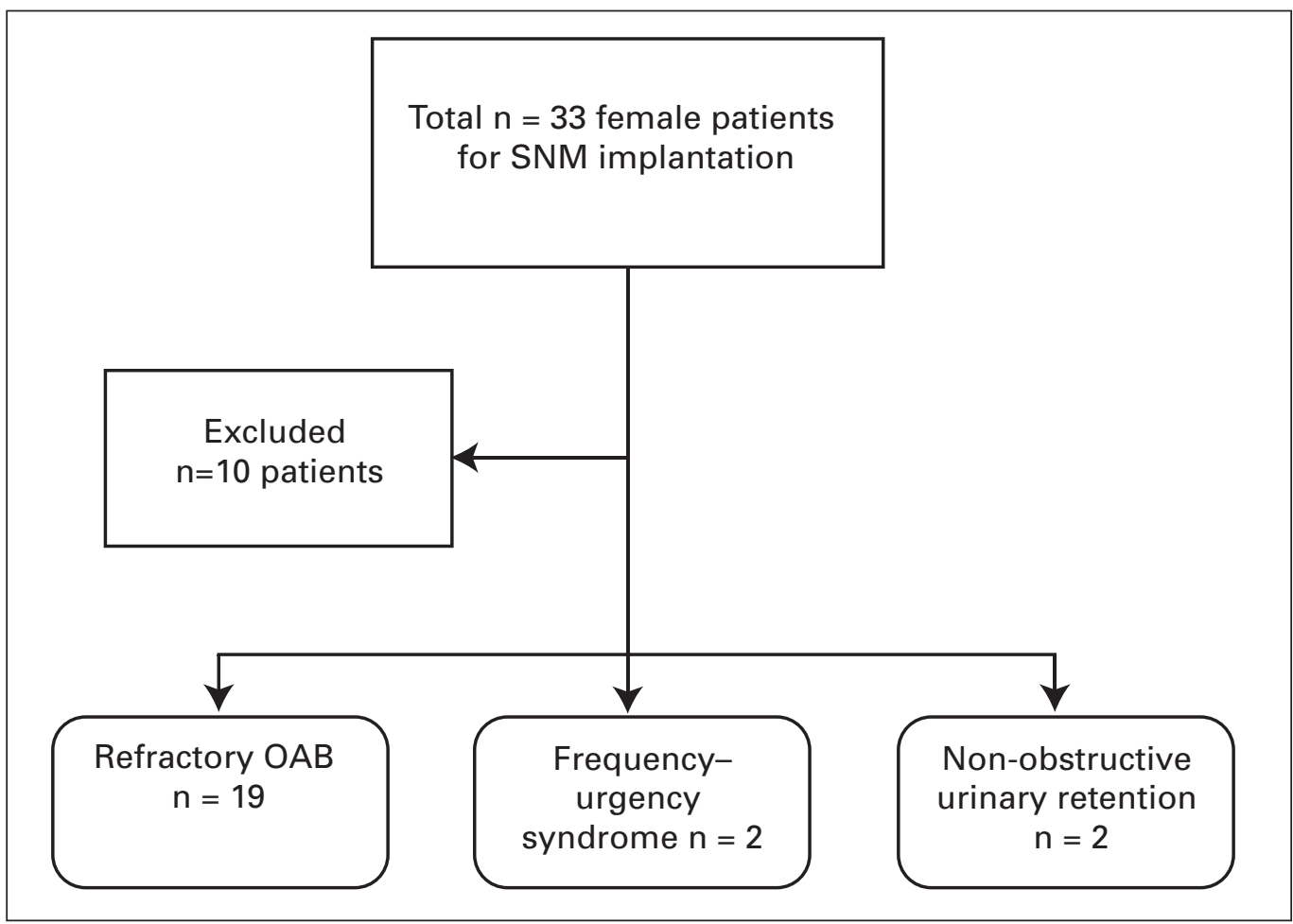

Fig. 1. Flow chart for total number of patients included and excluded in the study. SNM: sacral nerve modulation; $O A B$ : overactive bladder. 
Effect of SNM on female sexual function

\begin{tabular}{lccccccc}
\hline \multicolumn{2}{l}{ Table 2a. Female sexual function Index scores and domains which show significant improvement post-SNM implantation } \\
\hline $\begin{array}{l}\text { Category } \\
\mathbf{n = 2 3}\end{array}$ & $\begin{array}{c}\text { Total FSFI score } \\
\text { (Mean } \pm \text { SD) }\end{array}$ & $\begin{array}{c}\text { Desire } \\
\text { (Mean } \pm \text { SD) }\end{array}$ & $\begin{array}{c}\text { Arousal } \\
\text { (Mean } \pm \text { SD) }\end{array}$ & $\begin{array}{c}\text { Vaginal } \\
\text { lubrication } \\
\text { (Mean } \pm \text { SD) }\end{array}$ & $\begin{array}{c}\text { Orgasm } \\
\text { (Mean } \pm \text { SD) }\end{array}$ & $\begin{array}{c}\text { Sexual } \\
\text { satisfaction } \\
\text { (Mean } \pm \text { SD) }\end{array}$ & $\begin{array}{c}\text { Pain } \\
\text { (Mean } \pm \text { SD) }\end{array}$ \\
\hline Baseline & $15.49 \pm 9$ & $2.03 \pm 1$ & $2.35 \pm 1.7$ & $2.93 \pm 2.2$ & $2.5 \pm 1.92$ & $2.69 \pm 1.78$ & $2.89 \pm 2.66$ \\
Postoperative (SNM) & $18.33 \pm 10.96$ & $2.61 \pm 1$ & $2.8 \pm 1.96$ & $3.01 \pm 2.17$ & $2.99 \pm 2.31$ & $3.34 \pm 2.14$ & $3.5 \pm 2.71$ \\
$p$ value & 0.011 & 0.014 & 0.067 & 0.625 & 0.035 & 0.076 & 0.134 \\
\hline
\end{tabular}

SNM: sacral neuromodulation; FSFI: Female Sexual Function Index; SD: standard deviation.

\section{Discussion}

Female sexual dysfunction is common. The US National Health and Social Life Survey reported 43\% sexual dysfunction in females compared to $31 \%$ in males. ${ }^{21-23}$

The mechanism of female sexual dysfunction has several pathways, including psychogenic, neurogenic, musculogenic and hormonal factors, which all can cause arousal, desire, orgasmic and/or pain sexual disorders. ${ }^{24-26}$ The treatment of female sexual dysfunction is mainly focused on hormonal therapies, including estrogen and testosterone, which are not without risk. Most studies are done in postmenopausal women. ${ }^{27-36}$ The available evidence on the effectiveness of SNM in voiding dysfunction and bowel habits raises the question of the possible effect on the genital organs that share the same S3 nerve innervations.

\begin{tabular}{lcc}
\hline $\begin{array}{l}\text { Table } \mathbf{2 b} \text {. Female Sexual Function Index scores baseline } \\
\text { and post-SNM therapy total FSFI for all study included } \\
\text { patients }\end{array}$ & \\
\hline Patient & Baseline total FSFI & Post-SNM therapy total FSFI \\
\hline 1 & 27.9 & 29.1 \\
2 & 17.1 & 29.5 \\
3 & 14.3 & 15.6 \\
4 & 18.5 & 21.6 \\
5 & 14.3 & 27.8 \\
6 & 15.3 & 17.6 \\
7 & 17.1 & 29.5 \\
8 & 3.6 & 4.4 \\
9 & 16.5 & 21.6 \\
10 & 16.5 & 26.4 \\
11 & 28.9 & 29.5 \\
12 & 28.9 & 21.6 \\
13 & 29.7 & 29.5 \\
14 & 3.2 & 5.0 \\
15 & 18.3 & 20.7 \\
16 & 2.0 & 2.0 \\
17 & 2.3 & 1.8 \\
18 & 17.2 & 19.0 \\
19 & 3.5 & 3.8 \\
20 & 28.8 & 29.5 \\
21 & 22.0 & 29.5 \\
22 & 3.8 & 3.6 \\
23 & 4.4 & 3.0 \\
\hline
\end{tabular}

Our prospective, observational study demonstrates a statistically significant effect of SNM on FSFI $(p=0.011, \mathrm{CI}$ -5.1153 to -5.1153 ); this result is similar to other papers. ${ }^{37-41}$

Although female sexual dysfunction is defined as FSFI $\leq 26$, our study patients had low scores with mean FSFI baseline of $15 \pm 9$ and a mean post-SNM therapy FSFI of $18 \pm 10$, despite their statistically significance. In the literature, the cutoff point in the FSFI score to determine clinical improvement is undetermined; the FSFI is used as an assessment tool to detect any change post-therapy.

We found a significant improvement in desire and orgasm domains of the FSFI. The orgasm improvement could be due to the vibration sensation and electrical current at the pelvic area, while the desire improvement may be due to the SNM effect and the restoring activity associated with brainstem autoregulation and attenuation of cingulate activity. ${ }^{42}$ Quality of life improvements in the emotional role, general health and social function may also affect the desire in patients after SNM therapy. Conversely, in 7 patients Pauls and colleagues $^{37}$ found that all patients had significant improvement in total FSFI and all domains except arousal. Ingber and colleagues, however, failed to report any significant improvement after 6 months of SNM even after a subgroup analysis. ${ }^{43}$ Zahibi and colleagues used a different technique for SNM insertion and reported significant improvement in all domains and total FSFI score. ${ }^{38}$ In contrast, Lombardi and colleagues saw significant improvements in satisfaction and total FSFI scores. ${ }^{39}$

Our study showed improvement in 5 quality of life categories; this makes us question the indirect effect of SNM on sexual function. Correlation analysis showed no relation between FSFI score difference and all quality of life catego-

\begin{tabular}{lcc}
\hline $\begin{array}{l}\text { Table 3. Pearson correlation between the difference } \\
\text { in total FSFI score and age, diagnosis, BMI and UDI-6 } \\
\text { difference }\end{array}$ & \\
\hline Category & Pearson correlation coefficient & $\boldsymbol{p}$ value \\
\hline Diagnosis & -0.288 & 0.339 \\
Age & 0.028 & 0.899 \\
BMI & 0.065 & 0.769 \\
$\begin{array}{l}\text { Urinary symptom } \\
\text { improvement (UDI-6) }\end{array}$ & 0.898 \\
\hline $\begin{array}{l}\text { BMl: body mass index; UDI: Urinary Distress Inventory; FSFI: Female Sexual Function } \\
\text { Index. }\end{array}$ & -0.028 \\
\hline
\end{tabular}


Banakhar et al.

\begin{tabular}{|c|c|c|c|c|c|c|c|c|}
\hline $\begin{array}{l}\text { Category } \\
n=23\end{array}$ & $\begin{array}{c}\text { Physical } \\
\text { functioning } \\
\text { (Mean } \pm \text { SD) }\end{array}$ & $\begin{array}{l}\text { Physical role } \\
\text { (Mean } \pm \text { SD) }\end{array}$ & $\begin{array}{c}\text { Mental } \\
\text { health } \\
\text { (Mean } \pm \text { SD) }\end{array}$ & $\begin{array}{c}\text { Vitality } \\
\text { (Mean } \pm \text { SD) }\end{array}$ & $\begin{array}{c}\text { Emotional role } \\
\text { (Mean } \pm \text { SD) }\end{array}$ & $\begin{array}{c}\text { Social } \\
\text { functioning } \\
\text { (Mean } \pm \text { SD) }\end{array}$ & $\begin{array}{l}\text { Body pain } \\
\text { (Mean } \pm \text { SD) }\end{array}$ & $\begin{array}{c}\text { General } \\
\text { health } \\
\text { (Mean } \pm \text { SD) }\end{array}$ \\
\hline Baseline & $46.5 \pm 13.9$ & $40.2 \pm 48$ & $50.72 \pm 47$ & $26.52 \pm 21$ & $44.7 \pm 29$ & $44.7 \pm 29$ & $56.2 \pm 29.2$ & $35.7 \pm 19$ \\
\hline Postoperative (SNM) & $66.3 \pm 21$ & $42.4 \pm 23$ & $46.4 \pm 43$ & $42.4 \pm 25$ & $59.1 \pm 28.4$ & $70.1 \pm 28$ & $50.3 \pm 25.6$ & $53.4 \pm 23.05$ \\
\hline$p$ value & 0.00 & 0.845 & 0.710 & 0.00 & 0.005 & 0.00 & 0.985 & 0.001 \\
\hline
\end{tabular}

SNM: sacral nerve modulation; SD: standard deviation.

ries. It can be explained that urinary control contributes to improvements in quality of life that in turn results in better sexual performance; however, our study did not demonstrate any statistical significance due to our small sample size. Also, there was no correlation between the FSFI scores and age, BMI, primary diagnosis and urinary symptom on UDI-6. Interestingly, urinary symptom scores (UDI-6) demonstrated a significant correlation with the social functioning category; this is expected in these patients who face embarrassment and who tend to avoid social gathering due to their urinary symptoms. This result is similar to Pauls' reported lack of correlation between FSF improvement and urinary symptoms control. ${ }^{37}$ While Bradley and colleagues reported a trend between FSFI and changes in urinary symptoms, there was no significant association with their small study population $(n=10) .{ }^{40}$ In contrast, Signorello and colleagues reported a significant correlation between clinical improvement and improvement in sexual function, but their study is also limited by its small sample size. ${ }^{41}$

Our prospective study is limited by the sample small size, but in comparison to all the reported series, it included more patients $(n=23)$. Our study has the advantage of analyzing the confounding effect of other factors (quality of life, urinary symptoms, patient demographics), which were lacking in the previously reported studies.

\section{Conclusion}

SNM may improve FSFI in patients with voiding dysfunction. SNM may play a role in managing female sexual dysfunction in the future. We recommend the development of randomized controlled trials for the use of SNM in pure female sexual dysfunction using the staged procedure after excluding anatomical and psychogenic causes.
Competing interests: Dr. Banakhar, Dr. Gazwani, Dr. El Kelini, Dr. Al-Shaiii and Dr. Hassouna declare no competing financial or personal interests.

This paper has been peer-reviewed.

\section{References}

1. Hassouna $M$, Siegel $S$, Nyeholt $A$, et al. Sacral neuromodulation in the treatment of urgency- frequency symptoms: A multicenter study on efficacy and safety. J Urol 2000;163:1849-54. http://dx.doi. org/10.1016/S0022-5347(05)67558-1

2. Abrams P, Andersson KE, Birder L, et al. 4th International consultation on incontinence. Recommendations of the International Scientific committee: Evaluation and treatment of Urinary Incontinence, Pelvic Organ Prolapse and fecal Incontinence. Health Publication Ltd; Paris, France, 4th ed.; 2009.

3. Shaker HS, Hassouna M. Sacral root neuromodulation in idiopathic nonobstructive chronic urinary retention. J Urol 1998;159:1476-8. http://dx.doi.org/10.1097/00005392-199805000-00017

4. Alshaii $T$, Banakhar $M$, Hassouna M. Pelvic electrical neuromodulation for the treatment of overactive bladder symptoms. Adv Urol 2011;2011:757454. Epub 2011 May 14.

5. Banakhar M, Al-Shaiii T, Hassouna M. Sacral neuromodulation and refractory overactive bladder: An emerging tool for an old problem. Ther Adv Urol 2012;4:179-85. http://dx.doi.org/ $10.1177 / 1756287212445179$

6. Kruse MN, Noto H, Roppolo JR, et al. Pontine control of the urinary bladder and external urethral sphincter in the rat. Brain Res 1990;532:182. http://dx.doi.org/10.1016/0006-8993(90)91758-9

7. Kruse MN, de Groat WC. Spinal pathways mediate coordinated bladder/urethral sphincter activity during reflex micturation in normal and spinal cord injured neonatal rats. Neurosci Let 1993,152:141

8. Elkelini M, Hassouna M. Mechanisms of action of sacral neuromodulation. Int Urogynecol J 2010;21:S439-46.

9. Leng WW, Chancellor MB. How sacral nerve stimulation neuromodulation works. Urol Clin North Am 2005;32:11-8. http://dx.doi.org/10.1016/i.ucl.2004.09.004

10. Bernstein AJ, Peters KM. Expanding indications for neuromodulation. Urol Clin North Am 2005;32:59-63. http://dx.doi.org/10.1016/j.ucl.2004.10.002

11. Banakhar M, A-Shaii T, Hassouna M. Sacral neuromodulation in the treatment of interstitial cystitis/ painful bladder syndrome: Should it be off label? Curr Bladder Dysfunct Rep 2012;7:120-4. http:// dx.doi.org/10.1007/s1 1884-012-0122-2

12. Al-Zahrani AA, El Zayat EA, Gajewski JB. Long-term outcome and surgical interventions after sacral neuromodulation implant for lower urinary tract symptoms: 14 years' experience at 1 center. J Urol 2011;185:981-6.

13. Lukban J, Whitmore K, Sant G. Current management of interstitial cystitis. Urol Clin North Am 2002;29:649-60. http://dx.doi.org/10.1016/S0094-0143(02)00055-1

Table 5. Pearson correlation p value between quality of life domains and the difference in total FSFI score, age, BMI, and UDI-6 difference

\begin{tabular}{lcccccccc}
\hline $\begin{array}{l}\text { Category } \\
\mathbf{n = 2 3}\end{array}$ & $\begin{array}{c}\text { Physical } \\
\text { functioning }\end{array}$ & $\begin{array}{c}\text { Physical } \\
\text { role }\end{array}$ & $\begin{array}{c}\text { Mental } \\
\text { health }\end{array}$ & Vitality & $\begin{array}{c}\text { Emotional } \\
\text { role }\end{array}$ & $\begin{array}{c}\text { Social } \\
\text { functioning }\end{array}$ & $\begin{array}{c}\text { Body pain } \\
\text { General health }\end{array}$ \\
\hline Total FSFI score difference & 0.54 & 0.245 & 0.455 & 0.72 & 0.938 & 0.811 & 0.100 \\
Age & 0.59 & 0.39 & 0.25 & 0.25 & 0.41 & 0.212 & 0.646 & 0.598 \\
UDI-6 score difference & 0.215 & 0.13 & 0.40 & 0.7 & 0.252 & 0.047 & 0.37 & 0.36 \\
BMI & 0.88 & 0.27 & 0.16 & 0.8 & 0.712 & 0.623 & 0.93 & 0.071 \\
\hline
\end{tabular}

BMI: body mass index; UDI: Urinary Distress Inventory; FSFI: Female Sexual Function Index. 
14. Ghazwani YQ, Elkelini MS, Hassouna MM. Efficacy of sacral neuromodulation in treatment of bladder pain syndrome: Long-term follow-up. Neurourol and Urodyn 2011;30:1271-5. http://dx.doi.org/10.1002/ nau.21037. Epub 2011 May 6.

15. Everaert K, Devulder J, De Muynck M, et al. The pain cycle implications for the diagnosis and treatment of pelvic pain syndromes. Int Urogynecol J Pelvic Floor Dysfunct 2001;12:9-14. http://dx.doi. org/10.1007/s001920170087

16. Pascual I, Gonzalez, Gomez CC, et al. Sacral nerve stimulation for fecal incontinence. Rev Esp Enferm Dig 2011;103:355-9.

17. Siegel S, Paszkiewicz E, Kirkpatrick C, et al. Sacral nerve stimulation in patients with chronic intractable pelvic pain. J Urol 2001;166:1742-5. http://dx.doi.org/10.1016/S0022-5347(05)65665-0

18. Feler CA, Whitworth LA, Fernandez J. Sacral neuromodulation for chronic pain conditions. Anesthesiol Clin North America 2003;21:785-95. http://dx.doi.org/10.1016/S0889-8537(03)00085-3

19. Wiegel M, Meston C, Rosen R. The Female sexual function Index (FSFI): Cross validation and development of clinical cutoff scores. J Sex Marital Ther 2005;31:1-20. http://dx.doi. org/10.1080/00926230590475206

20. Laumann E0, Paik A, Rose RC. Sexual dysfunction in the United States: Prevalence and predictors. JAMA 1999;281:537-44. http://dx.doi.org/10.1001/jama.281.6.537

21. Berman JR, Adhikari SP, Goldstein I. Anatomy and physiology of female sexual function and dysfunction: Classification, evaluation and treatment options. Eur Urol 2000;38:20-9. http://dx.doi. org/10.1159/000020247

22. Leiblum SR. Definition and classification of female sexual disorders. Int I Impot Res 1998;10:S104-6.

23. Meston CM, Frohlich PF. Update on female sexual function. Curr Opin Urol 2001;11:603-9. http:// dx.doi.org/10.1097/00042307-200111000-00008

24. Meston CM, Frohlich PF. The neurobiology of sexual function. Arch Gen Psychiatry 2000;57:1012-30. http://dx.doi.org/10.1001/archpsyc.57.11.1012

25. Nusbaum MRH, Hamilton C, Lenahan P. Chronic illness and. sexual functioning. Am Fam Physician 2003;67:347-54

26. Sarrell P. Progestogens and blood flow. Int Proc J 1989;1:266-71.

27. Sarrell PM. Sexuality and menopause. Obstet Gynecol 1990;75:265-30S.

28. Hilditch JR, Lewis J, Ross AH. A comparison of the effects of oral conjugated equine estrogen and transdermal estradio-17-beta combined with an oral progestin on quality of life in postmenopausal women. Maturitas 1996;24:177-84. http://dx.doi.org/10.1016/S0378-5122(96)82007-X

29. Shifren JL, Braunstein GD, Simon JA, et al. Transdermal testosterone treatment in women with impaired sexual function after oophorectomy. N Engl J Med 2000;343:682-8. http://dx.doi.org/10.1056/ NEJM200009073431002

30. Sherwin BB, Gelfand MM, Brender W. Androgen enhances sexual motivation in females: A prospective, crossover study of sex steroid administration in the surgical menopause. Psychosomatic Med 1985;47:33951. http://dx.doi.org/10.1097/00006842-198507000-00004
31. Sarrel P, Dobay B, Wiita B. Estrogen and estrogen-androgen replacement in postmenopausal women dissatisfied with estrogen-only therapy. J Reprod Med 1998;43:847-56.

32. Writing Group for the Women's Health Initiative Investigators. Risks and benefits of estrogen plus progestin in healthy postmenopausal women: Principal results from the women's health initiative randomized controlled trial. JAMA 2002;288:321-33. http://dx.doi.org/10.1001/jama.288.3.321

33. Hulley $\mathrm{S}$, Furberg C, Barrett-Connor $\mathrm{E}$, et al. Noncardiovascular disease outcomes during 6.8 years of hormone therapy: Heart and estrogen/progestin replacement study follow-up (HERS II). JAMA 2002;288:5866. http://dx.doi.org/10.1001/jama.288.1.58

34. Grady D, Herrington D, Bittner V, et al. Cardiovascular disease outcomes during 6.8 years of hormone therapy: Heart and estrogen/ progestin replacement study follow-up (HERS II). JAMA 2002;288:49-57. http://dx.doi.org/10.1001/jama.288.1.49

35. Hulley S, Grady D, Bush T, et al. Randomized trial of estrogen plus progestin for secondary prevention of coronary heart disease in postmenopausal women. JAMA 1998;280:605-13. http://dx.doi. org/10.1001/jama.280.7.605

36. Pauls RN, Marinkovic SP, Silva WA, et al. Effects of sacral neuromodulation on female sexual function. Int Urogynecol J Pelvic Floor Dysfunct 2007;18:391-5. http://dx.doi.org/10.1007/s00192-006-0168-9

37. Zahibi N, Mourtzinos A, Maher MG, et al. The effects of bilateral caudal epidural S2-4 neuromodulation on female sexual function. Int Urogynecol J Pelvic Floor Dysfunct 2008; 19:697-700.

38. Lombardi G, Mondaini N, Macchiarella A, et al. Clinical female sexual outcome after sacral neuromodulation implant for lower urinary tract symptom (LUTS). J Sex Med 2008;5:1411-7.

39. Gill BC, Swartz MA, Firoozi F, et al. Improved sexual and urinary function in women with sacral nerve stimulation. Neuromodulation 2011;14:436-43. http://dx.doi.org/10.1111/i.1525-1403.2011.00380.x

40. Signorello D, Seitz CC, Berner L, et al. Impact of sacral neuromodulation on female sexual function and his correlation with clinical outcome and quality of life indexes: A monocentric experience. I Sex Med 2011;8:1147-55. http://dx.doi.org/10.1111/i.1743-6109.2010.02189.x

41. Ingber MS, Ibrahim IA, Killinger KA, et al. Neuromodulation and female sexual function: Does treatment for refractory voiding symptoms have an added benefit? Int Urogynecol I Pelvic Floor Dysfunct 2009;20:1055-9. http://dx.doi.org/10.1007/s00192-009-0900-3

42. Dasgupta R, Critchley HD, Dolan RJ, et al. Changes in brain activity following sacral neuromodulation for urinary retention. J Urol 2005; 174:2268-72. http://dx.doi.org/10.1097/01.ju.0000181806.59363.dl

43. Jarrett MED, Nicholls RJ, Kamm MA. Effect of sacral neuromodulation for faecal incontinence on sexual activity. Colorectal Dis 2005;7:523-5. http://dx.doi.org/10.1111/j.1463-1318.2005.00815.x

Correspondence: Dr. Mai Ahmed Banakhar, Department of Urology, King Abdulaziz University, Faculty of Medicine, Jeddah, Kingdom of Saudi Arabia; drmaibanakher@hotmail.com 